\title{
Discurso con motivo del centenario de Ralph Waldo Emerson
}

\author{
por William James
}

(Concord, Massachusetts, 25 de mayo de 1903).

El discurso que se presenta a continuación fue leído por William James con ocasión del aniversario de la muerte del gran poeta y ensayista norteamericano Ralph Waldo Emerson. Es el retrato de uno de los maestros del pensamiento y la lengua norteamericana, quien a su vez retrató a otros personajes como Miguel Ángel y Milton, y cuya figura fue esbozada por más de un grande de su tiempo -además de James, encontramos el Emerson de Edgar Lee Masters -. El discurso de James, así como el estudio de Lee Masters, serán editados en el volumen Miguel Ángel. Milton de Ralph Waldo Emerson, a publicarse en octubre de 2008 en la casa editorial Los libros de Homero. La traducción del discurso y las notas son de Jorge F. Morales.

El pathos de la muerte es éste: que cuando los días de la vida se terminan, esos días que estaban tan atestados de asuntos y que se sentían tan pesados al pasar, lo que permanece de uno en la memoria debería ser normalmente algo insignificante. El fantasma de una actitud, el eco de un cierto modo de pensar, unas cuantas páginas impresas, un invento o alguna victoria obtenida en un breve momento crítico, es todo lo que puede sobrevivir al mejor de nosotros. Es como si la totalidad del significado de un hombre se hubiera reducido ahora al fantasma de una actitud, a una mera nota musical o una sugestiva frase de su singularidad. Son felices aquellos cuya singularidad ofrece una nota tan clara como para salir victoriosa sobre la inevitable pena de semejante disminución y reducción.

Un espectro ideal como éste, con la personalidad de Emerson, flota hoy en el aire sobre todo Concord tomando, en las mentes de aquellos de ustedes que fueron sus vecinos e íntimos amigos, una forma un tanto más completa, permaneciendo más abstracta para 
la nueva generación, pero haciéndonos notar a todos la importancia de la noción de un espíritu indescriptiblemente precioso. La forma que tan tarde se movió hacia estas calles y caminos, o que aguardó en estos campos y bosques las amadas visitas de la Musa, es ahora polvo; pero la nota del alma, la voz espiritual se eleva fuerte y claro sobre el escándalo de los tiempos y parece firmemente destinada a ejercer una influencia ennoblecedora sobre las generaciones futuras.

Lo que dio un sabor incomparable a la individualidad de Emerson fue, incluso más que sus ricos dones mentales, su combinación. Raramente ha sabido un hombre con tal precisión los límites de su genio o tan indefectiblemente ha permanecido dentro de ellos. «Sé fiel a tu orden» ${ }^{1}$, solía decir a los estudiantes jóvenes; y tal vez la impresión más grande que se tiene de su vida es la lealtad a su propia categoría y misión. La categoría era aquella que gustaba denominar «erudito», quien percibe la verdad pura; y la misión era la de reportar en todo su valor cada percepción. Un buen día, decía, es en el que tenemos la mayor cantidad de percepciones ${ }^{2}$. Hay momentos en los que el graznido de un cuervo, una mala hierba, un copo de nieve o un granjero plantando su campo se convierten en símbolos de verdades para el intelecto iguales a aquéllas que los fenómenos más majestuosos pueden abrir ${ }^{3}$. Permítanme hacerme cargo de mi propia responsabilidad, después, caminar en soledad, consultar el cielo, el campo y el bosque, esperando diligentemente cada mañana por las noticias sobre la estructura del universo que el buen Espíritu me dará.

Esta era la primera mitad de Emerson, pero sólo la mitad; pues su genio estaba ávido de expresión, y su verdad debía estar ataviada con la prenda verbal adecuada. La forma de la prenda era tan

${ }^{1}$ En «The Man of Letters». The Complete Works of Ralph Waldo Emerson. Centenary Digital Edition (www.rwe.org). Volume X: Lectures and Biographical Sketches, 1884. Discurso ofrecido ante The Literary Societies of Waterville College (hoy Colby College) en 1863.

2 En «Inspiration». The Complete Works of Ralph Waldo Emerson. Centenary Digital Edition. Volume VIII: Letters and Social Aims, 1876.

3 Cf. «The Natural History of Intellect». The Complete Works of Ralph Waldo Emerson. Centenary Digital Edition. Volume XII: The Natural History of Intellect and Other Papers, 1893. 
vital en Emerson que es imposible separarla de la materia. Forman una combinación química. Pensamientos que habrían sido triviales expresados de otra manera, son importantes a través de los sustantivos y verbos con los que él los casaba. El estilo es el hombre, como se ha dicho; el hombre que la misión de Emerson culminó en su estilo, y si tuviéramos que definirlo en una sola palabra, lo tendríamos que llamar Artista. Era un artista con un medio verbal, forjado en material espiritual.

Este deber espiritual de observar y reportar determinó todo el tenor de su vida. Fue para proteger este deber de la invasión y la distracción que vivió en el campo, y consistentemente declinó a enmarañarse con asociaciones o a estar cargado de funciones que, sin importar cuánto creyera en ellas, sintió eran deberes para otros hombres y no para él. Inclusive encontraba el cuidado de su jardín, «con sus encorvamientos y manoseos en el espacio de unas cuantas yardas», «restrictivo y venenoso», y se entregaba sin excusa, en cambio, a largas caminatas errantes y vagabundeos ${ }^{4}$. Innumerables «causas» buscaron enlistarlo como su «colaborador» - todas obtuvieron su sonrisa y palabras de simpatía, pero ninguna lo atrapó en el servicio. La lucha en contra de la esclavitud misma, profundamente atraído por ella, lo encontró firme: «Dios debe gobernar su propio mundo, y conoce el camino fuera de esta fosa sin que yo abandone mi puesto, que no tiene a nadie más que a mí para que lo custodie. Tengo que enfrentar unos esclavos bastante distintos a esos negros, a saber, pensamientos aprisionados en lo más profundo del cerebro del hombre, y que no tienen otro vigía o amante o defensor que yo ${ }^{5}$. Esto en respuesta a las posibles interrogantes de su consciencia. Para moralistas apasionados con ideas más objetivas del deber, semejante fidelidad a los límites de su genio muy a menudo le hicieron parecer provocadoramente distante y ocupado; pero los que podemos ver las cosas desde una perspectiva más liberal aprobamos de manera incondicional los resultados. El tacto

${ }^{4}$ Cf. «Wealth». The Complete Works of Ralph Waldo Emerson. Centenary Digital Edition. Volume VI: Conduct of Life, 1860.

${ }^{5}$ En Journals (agosto de 1852), Edward Emerson ed., Boston: Houghton Mifflin, 19041914, vol. VIII. 
impecable con el que mantuvo sus límites a salvo mientras se mantuvo impávidamente dentro de ellos es un ejemplo para alentar a otros teóricos y artistas de todo el mundo.

La perspicacia y el credo que siguió la vida de Emerson pueden ser resumidos mejor por su propio verso:

¡Tan próxima está la grandeza de nuestro polvo,

Tan cerca está Dios del hombre! ${ }^{6}$

A través del hecho individual siempre brilló para él la refulgencia de la Razón Universal. El gran Intelecto Cósmico termina y se aloja en hombres mortales y horas transitorias. Cada uno de nosotros es un ángulo de su visión eterna y la única manera de ser fiel con nuestro Creador es ser leales con nosotros mismos. « $¡$ Oh Hombre rico y diverso!», exclama, «tú, palacio de la vista y el sonido, llevando en tus sentidos la mañana y la noche y la galaxia insondable; en tu cerebro la geometría de la ciudad de Dios; en tu corazón la morada del amor y los reinos de lo justo y de lo injusto» ${ }^{7}$.

Si el individuo se abre así, directamente al Absoluto, se sigue que hay algo en cada uno de nosotros, incluso en el más modesto, que no debe consentir en tomar prestadas tradiciones y en vivir de segunda mano. «¿Si Juan era perfecto, por qué estamos tú y yo vivos?», escribe Emerson. «Mientras exista algún hombre hay alguna necesidad de él; dejemos que luche por sí mismo» ${ }^{8}$. Esta fe en que en una vida de primera mano hay algo sagrado es quizá la nota más característica en los escritos de Emerson. Su lado más ardiente es esta creencia no conformista, y si su temperamento alguna vez pudo estar al borde de la irascibilidad común, habría sido por el carácter apasionado de sus sentimientos sobre este punto. El mundo es todavía nuevo e inexperimentado. Al ver con frescura, y sin

${ }^{6}$ En «Voluntaries». The Complete Works of Ralph Waldo Emerson. Centenary Digital Edition. Volume IX: Poems, 1847.

7 En «The Method of Nature». The Complete Works of Ralph Waldo Emerson. Centenary Digital Edition. Volume I: Nature; Addresses, \& Lectures, 1841. Discurso solemne ofrecido ante la Society of the Adelphi, en Waterville College, Maine, el 11 de agosto de 1841.

${ }^{8}$ En «Nominalist and Realist». The Complete Works of Ralph Waldo Emerson. Centenary Digital Edition. Volume III: Essays II, 1844. 
escuchar lo que otros han visto, debe encontrar el hombre en qué consiste la verdad. «Cada uno de nosotros puede deleitarse en el gran amanecer que despunta por el Mar del Este, y ser él mismo uno de los hijos de la luz»9 . «Confía en ti mismo, todos los corazones vibran con esa cuerda de hierro. Hay un momento en la educación de todo hombre en que se debe arribar a la convicción de que la imitación es suicidio; en que se debe asumir a sí mismo para bien o para mal como su fortuna; y saber que aunque el vasto universo esté lleno de bien, no podrá obtener ni un grano de maíz nutritivo sino a través del trabajo duro vertido en la parcela de tierra que le fue otorgada para cultivar» ${ }^{10}$.

Esta elocuencia sin par con la que Emerson proclamó la soberanía del individuo viviente electrificó y emancipó a su generación, y este toque del clarín sin duda será considerado por futuros críticos como el alma de su mensaje. El hombre presente es la realidad original, la institución es derivada, y el hombre pasado es irrelevante y eliminado para asuntos presentes. «Si alguien hachara tu árbol con el texto de Juan 1:7, o con una [complicada] máxima de san Pablo, dile», escribió Emerson, «'Mi árbol es Yggdrasil, el árbol de la vida'. Hazle saber con tu seguridad, que tu convicción es absoluta y suficiente, y, si fuera Pablo mismo, que tú también estás aquí y con tu Creador» ${ }^{11}$. «Nunca te adhieras a Dios», insistía, «en contra del nombre de Dios» ${ }^{12}$. De modo que, a pesar del carácter intensamente religioso de la totalidad de su pensamiento, cuando comenzó su carrera le pareció a muchos de sus hermanos de profesión clerical que era poco más que un iconoclasta y un profanador.

La creencia de Emerson de que el individuo debe justificadamente adecuarse a la vocación para la cual el Espíritu del mundo lo ha llamado al ser es la fuente de esas sublimes páginas, alentadoras

${ }^{9}$ Cf. Nota 7.

10 En «Self-Reliance». The Complete Works of Ralph Waldo Emerson. Centenary Digital Edition. Volume II: Essays I, 1841.

11 En «The Sovereignity of Ethics». The Complete Works of Ralph Waldo Emerson. Centenary Digital Edition. Volume X: Lectures and Biographical Sketches, 1884.

12 En «The Natural History of Intellect». The Complete Works of Ralph Waldo Emerson. Centenary Digital Edition. Volume XII: The Natural History of Intellect and Other Papers, 1893. 
y soportes de nuestra juventud, en las que insta a quienes le escuchan a ser incorruptiblemente fieles con su propia consciencia privada. Nada puede lastimar al hombre que permanece en su lugar y carácter designados. Un hombre así es invulnerable; él equilibra el universo, lo equilibra tanto al permanecer pequeño cuando él es pequeño, como al ser grande y extenderse cuando él es grande. «Amo y honro a Epaminondas», dijo Emerson, «pero no quiero ser Epaminondas. Considero más justo amar el mundo de estos tiempos que el mundo de sus tiempos. Ni puedes, si soy auténtico, provocarme la más mínima inquietud al decir: 'Él actuó y tú permaneces inmóvil'. Yo considero buena a la acción cuando hay necesidad de ella, y sentarse inmóvil también es bueno. Epaminondas, si era el hombre que considero era, se hubiera sentado inmóvil con alegría y paz, si su suerte hubiera sido la mía. El cielo es grande, y ofrece espacio para todos los modos de amor y fortaleza» ${ }^{13}$. «El hecho de que esté aquí ciertamente me muestra que el alma tiene necesidad de un órgano aquí, y, ¿acaso no debo asumir el puesto?» ${ }^{14}$.

La vanidad de toda superutilidad y pretensión nunca fue explicada más afortunadamente que por Emerson en los diversos pasajes en los que desarrolla este aspecto de su filosofía. El carácter se proclama infaliblemente a sí mismo. «iEsconde tus pensamientos! Esconde al sol y a la luna. Ellos se publican al universo. Ellos hablarán a través de ti aunque seas mudo. Ellos manarán de tus acciones, tus costumbres y tu rostro ${ }^{15}$. [...] No digas cosas: lo que eres te vigila todo el tiempo y retruena de tal manera que no puedo escuchar lo que dices en sentido contrario ${ }^{16}$. [...] Lo que un hombre es se graba sobre él en letras de luz. El ocultamiento le es vano, sin alarde. Hay una confesión en las miradas de nuestros ojos; en nuestras sonrisas; en los saludos; y al tomarnos las manos. Su pecado lo embadurna,

13 En «Spiritual Laws». The Complete Works of Ralph Waldo Emerson. Centenary Digital Edition. Volume II: Essays I, 1841.

14 Cf. Nota 13.

15 En «Literary Ethics». The Complete Works of Ralph Waldo Emerson. Centenary Digital Edition. Volume I: Nature; Addresses, \& Lectures, 1841. Discurso solemne ofrecido ante The Literary Societies of Dartmouth College, el 24 de julio de 1838.

16 En «Social Aims». The Complete Works of Ralph Waldo Emerson. Centenary Digital Edition. Volume VIII: Letters and Social Aims, 1876. 
estropea toda su buena impresión. Los hombres desconocen por qué no confían en él, pero no confían en él. Su vicio vuelve vidrioso el ojo, arroja líneas de expresión mezquina en la mejilla, pellizca la nariz, coloca la marca de la bestia en la nuca, y escribe, joh tonto, tonto!, en la frente de un rey. Si no vas a ser conocido por hacer algo, nunca lo hagas; un hombre puede jugar al tonto en las dunas de un desierto, pero cada grano de arena parecerá mirarlo. ¿Cómo puede un hombre ser ocultado? ¿Cómo puede él ser ocultado?» ${ }^{17}$.

Por otra parte, jamás se perdió totalmente una palabra sincera o un pensamiento sincero. «Jamás se echó por tierra la magnanimidad, pues hay ahí algún corazón que inesperadamente le da la bienvenida y la acepta. [...] El héroe no teme que ante su resistencia a confesar un acto justo y valiente, éste pase inadvertido y sin ser amado. Alguien lo sabe - él mismo - y lo empeña a la dulzura de la paz y a la nobleza de propósitos, que al final probarán ser una mejor proclamación que el relato del episodio» ${ }^{18}$.

El mismo derecho indefectible de ser exactamente lo que uno es, a condición sólo de ser auténtico, se despliega a sí mismo, según la manera de pensar de Emerson, de personas a cosas y a tiempos y lugares. Ninguna fecha, ninguna posición es insignificante, si la vida que las llena es genuina:

En soledad, en una aldea remota, la juventud ardiente pierde el tiempo y se lamenta. Con los ojos en llamas, en este descampado somnoliento, él ha leído la historia del emperador Carlos Quinto hasta que su fantasía ha clarificado a los bosques de los alrededores el tenue rugido de los cañonazos en la región milanesa y las marchas en Alemania. Le intriga el día de ese hombre. ¿Qué lo llenó? ¿Las numerosas órdenes, las decisiones severas, los partes extranjeros, la etiqueta castellana? El alma contesta: ¡contempla su día aquí! En los suspiros de estos bosques, en la tranquilidad de estos campos grises, en la brisa fresca que emana claramente de estas montañas del Norte; en los obreros, en los muchachos o en las señoritas que conozcas; en las esperanzas de la mañana, en el aburrimiento del medio día, y en los paseos de la tarde; en las comparaciones inquietantes; en los remordimientos ante la falta 
de vigor; en la gran idea y la penosa ejecución: contempla el día de Carlos Quinto; otro, aunque el mismo; contempla el día de Chatham, de Hampden, de Bayard, de Alfredo, de Escipión, de Pericles, - día de todos los que han nacido de mujer. La diferencia de circunstancias es meramente un atavío. Estoy probando la mismísima vida - su dulzura, su grandeza, su dolor, que tanto admiro en otros hombres. No preguntes tontamente al inescrutable y destruido pasado lo que no puede decir - los detalles de esa naturaleza, de ese día, llamados Byron o Burke-, pregúntale mejor sobre el envolvente Presente... Sé señor de un día, y podrás guardar tus libros de historia ${ }^{19}$.

Así es como «el hoy profundo que todos los hombres desprecian» recibe de Emerson una espléndida reivindicación. «¡Otro mundo! No hay otro mundo». Toda la vida de Dios se manifiesta en el individuo particular, y el aquí y el ahora, o ningún lugar, son la realidad. «El momento presente es el momento decisivo, y cada día es el día del Juicio Final $»^{20}$.

Semejante convicción de que la Divinidad está en todas partes fácilmente puede hacer de uno un optimista sentimental que se rehúsa a hablar mal de nada. La drástica percepción de Emerson de las diferencias lo mantuvo en el polo opuesto de esta debilidad. Después de haber visto a los hombres unas cuantas veces, podría decir, los encuentras a casi todos parecidos a sus graneros y despensas, muy pronto tan mohosos y monótonos. Nunca hubo un amante tan exigente del significado y la distinción, y nunca un ojo tan agudo para su descubrimiento. Su optimismo no tenía nada en común con esos vítores indiscriminados al Universo con los que Walt Whitman nos familiarizó. Para Emerson, el hecho y momento individuales estaban en realidad bañados de resplandor absoluto, pero era gracias a una condición que se salvaba la situación: debían ser especímenes valiosos - sinceros, auténticos, arquetípicos; debían haber hecho conexión con lo que él llamaba Sentimiento Moral $^{21}$, debían actuar de algún modo como portavoces simbóli-

${ }^{19}$ Cf. Nota 16.

${ }^{20}$ En «Works and days». The Complete Works of Ralph Waldo Emerson. Centenary Digital Edition. Volume VII: Society and Solitude, 1870.

${ }^{21}$ Cf. «Divinity School Address». The Complete Works of Ralph Waldo Emerson. Centenary 
cos del significado del Universo. Saber qué es lo que actúa exactamente de esta manera y qué no hace una verdadera conexión, es el secreto (de algún modo incomunicable, debe ser confesado) de la clarividencia, y sin duda no debemos esperar del clarividente una consistencia demasiado rigurosa. Emerson mismo era un verdadero clarividente. Podía percibir la miseria completa del hecho individual, pero también podía ver la transfiguración. Fácilmente se podría haber encontrado a sí mismo diciendo de algún agitador actual en contra de nuestra conquista Filipina ${ }^{22}$ lo que dijo de éste o aquél reformador de su propio tiempo. Lo podría haber llamado, como persona privada, un pelmazo tedioso y pusilánime. Pero infaliblemente habría agregado lo que entonces agregó: «Es extraño y horrible decir esto, pues siento que bajo él y su parcialidad y unicidad está la tierra y el mar, y todo lo que dentro de ellos existe, y el eje alrededor del cual gira el Universo pasa a través de su cuerpo donde él se encuentra» ${ }^{23}$.

Sea como sea, entonces, esta es la revelación de Emerson: la punta de cualquier pluma puede ser epítome de la realidad; el acto más común de una persona, si es realizado genuinamente, puede permanecer asido a la eternidad. Esta visión es la fuente primaria de todas sus exclamaciones; y es por esta verdad, vedada a todo artista literario previo para expresar en tonos tan penetrantemente persuasivos, que la prosperidad lo reconocerá como profeta, y quizá desatendiendo otras páginas, piadosamente volverá a aquellas que comunican este mensaje. Su vida fue una larga conversación con lo divino e invisible, expresándose a través de individuos y particulares: «¡Tan próxima está la grandeza de nuestro polvo, tan cerca está Dios del hombre! ${ }^{24}$.

Digital Edition. Volume I: Nature; Address \& Lectures, 1836-44. Discurso ofrecido ante el Divinity College, Cambridge, el 15 de julio de 1838. En este discurso, Emerson afirma que «la intuición del sentimiento moral es una percepción de la perfección de las leyes del alma».

22 Cf. William James, «Address on the Philippine Question», Proceedings of the Fifth Annual Meeting of the New England Anti-Imperialist League, diciembre de 1903.

${ }^{23}$ En Journals (mayo de 1844 - marzo de 1845), Edward Emerson ed., Boston: Houghton Mifflin, 1904-1914, vol. V. Cf. John Jay Chapman. Emerson and Other Essays. New York: AMS Press, 1899.

${ }^{24}$ Cf. Nota 6. 
Hablé de qué tan reducido es el espectro, qué tan delgado es el eco de los hombres después de su partida. El espectro de Emerson viene ahora hacia mí como si fuera la mismísima voz de este argumento vencedor. Sus palabras a este respecto seguramente serán citadas y extraídas más y más conforme avance el tiempo, y tomarán su lugar entre las Escrituras de la humanidad. «Contra la muerte y toda enemistad del olvido saldrás adelante ${ }^{25}$, amado Maestro. Mientras nuestra lengua inglesa perdure, los corazones de los hombres se alegrarán y sus almas se fortalecerán y liberarán gracias a las nobles y musicales páginas con las que la has enriquecido. 